\title{
PEMISAHAN GADOLINIUM SEBAGAI CONTRAST AGENT PADA MRI (MAGNETIC RESONANCE IMAGING) DENGAN LIGAN ASAM DI-(2-ETILHEKSIL)FOSFAT (D2EHPA) DAN TRIBUTILFOSFAT (TBP) SECARA EKSTRAKSI CAIR-CAIR DENGAN PELARUT ORGANIK - KEROSIN
}

\author{
Senadi Budiman ${ }^{1, *}$, Husein H. Bahti², Abdul Mutalib², Anni Anggraeni² \\ ${ }^{1}$ Jurusan Kimia Fakultas MIPA UNJANI, Cimahi, Jawa Barat \\ 2 Jurusan Kimia Fakultas MIPA UNPAD, Bandung, Jawa Barat \\ *Corresponding author email: senadiunjani@yahoo.com
}

\begin{abstract}
Abstrak
Gadolinium pada industri kesehatan banyak digunakan sebagai bahan baku pembuatan contrast agent sebagai Gd-DTPA pada MRI. Gadolinium adalah salah satu unsur tanah jarang golongan menengah dan terdapat dalam mineral monasit. Telah dilakukan penelitian terhadap pemisahan Gd(III) menggunakan ligan TBP, ligan D2EHPA dan campuran ligan TBP dan D2EHPA ( $1: 1 ; 1: 2$ dan $2: 1$ ), disertai pengaruh waktu ekstraksi 10 dan 15 menit serta volume larutan Gd(III) $30 \mathrm{~mL}$ dan $50 \mathrm{~mL}$. Diperoleh hasil pada kondisi terbaik untuk pengikatan Gd(III) yaitu pada waktu ekstraksi 10 menit dan volume larutan Gd(III) $30 \mathrm{~mL}$. Komposisi ligan yang baik pada TBP : D2EHPA (1:2).
\end{abstract}

Kata kunci : Unsur tanah jarang (UTJ), Ligan TBP dan $D_{2} E H P A$, Kerosin, Ekstraksi cair-cair

Submitted on: 8 November $2017 \quad$ Accepted on: 28 December 2017

DOI: https://doi.org/10.25026/jsk.v2i4.88

\section{PENDAHULUAN}

MRI (Magnetic Resonance Imaging) merupakan alat diagnostik untuk memeriksa dan mendeteksi tubuh menggunakan medan magnet besar, gelombang frekuensi radio, tanpa operasi, tanpa penggunaan sinar $\mathrm{X}$, ataupun bahan radioaktif (Hanson, 2009).

Contrast agent merupakan media yang digunakan untuk memperbaiki visibilitas struktur tubuh internal pada MRI.Secara umum, manipulasi kontras pada MRI dengan penerapan dan sangat berguna bila yang melekat tidak dapat dicapai dengan baik. Gadolinium merupakan unsur yang digunakan untuk contrast agent sebagai Gd-DTPA (Fjerdrumsmoen, 2004).

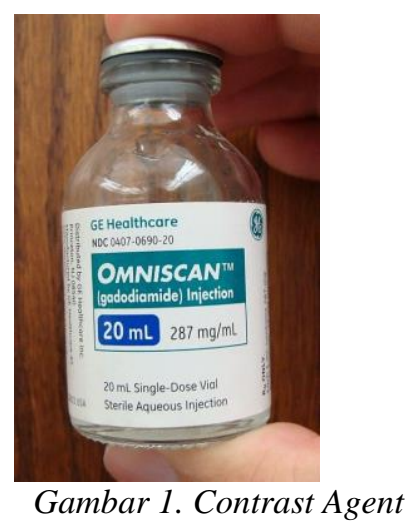

Gadolinium merupakan bagian dari unsur tanah jarang (UTJ) yang keberadaannya sangat sedikit di alam. Mineralnya tersusun dalam kompleks fosfat dan karbonat. Pada perkembangan teknologi pengolahan material, UTJ 
semakin dibutuhkan pada industri seperti industri kesehatan (Suwargi dkk, 2010).

Proses pemisahan dan pemurnian individual UTJ dapat dilakukan antara lain dengan cara pengendapan, kristalisasi, ekstraksi cair-cair, dan kromatografi pertukaran ion (Biyantoro, 2008 ; Gupta, 2005). Pemisahan ytrium (Y), disprosium (Dy), dan gadolinium (Gd) dengan ligan yang akan digunakan yaitu TBP dan D2EHPA dalam pelarut kerosen dari olah pasir senotim dilakukan secara ekstrasi cair-cair (Handini, 2017).

Kerosin diplih sebagai pelarut karena mempunyai titik didih yang besar sekitar $180-250^{\circ} \mathrm{C}$. D2EHPA telah banyak digunakan untuk pemisahan dan pemurnian UTJ karena selektifitasnya tinggi (Tomita et al., 2003).

Didasarkan latar belakang ini, maka dilakukan penelitian mengenai pengaruh kelarutan $\mathrm{Gd}(\mathrm{III}) \quad$ menggunakan komposisi ligan D2EHPA dan TBP dalam pelarut kerosin secara ekstraksi pelarut.

Pulau Bangka yang di kenal dengan penghasil tambang biji timah memiliki kelimpahan UTJ yang cukup besar dari hasil samping pertambangan biji timah tersebut (Rodliyah, 2015). Dari Pulau Bangka diperoleh berbagai logam lantanida, salah satunya logam gadolinium karena memiliki potensi di berbagai bidang keilmuan, seperti kesehatan salah satunya dimana pada masa mendatang diperkirakan penggunaan UTJ akan meluas (Suprapto, 2009). Umumnya UTJ dapat dijumpai bersama-sama dengan endapan timah. Penambangan dan pengolahan timah biasanya menghasilkan produk sampingan berupa mineral monasit yang mengandung UTJ. (Suprapto, 2009).

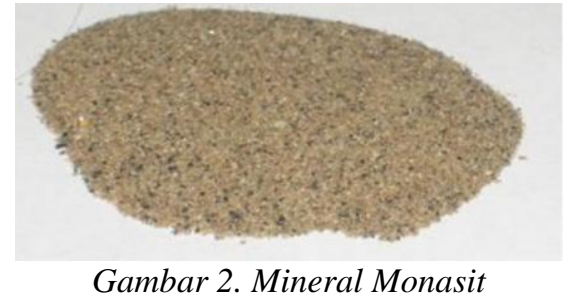

Menurut Fontana dan Loris (2009) secara konvensional UTJ dibagi menjadi tiga kelompok :

1. UTJ ringan, terdiri dari lanthanum $(\mathrm{La})$, Serium $(\mathrm{Ce})$, praseodimium (Pr), yttrium (Y) dan neodimium $(\mathrm{Nd})$.

2. UTJ sedang, terdiri dari samarium $(\mathrm{Sm})$, europium $(\mathrm{Eu})$, gadolinium $(\mathrm{Gd})$, terbium $(\mathrm{Tb})$ dan disprosium (Dy).

3. UTJ kelompok berat, terdiri dari holmium (Ho) sampai lutenium (Lu).

\section{Gadolinium}

Berwarna putih keperakan, berkilau seperti logam dan mudah ditempa. Pada suhu kamar mengkristal dalam bentuk heksagonal atau bentuk $\alpha$ dengan kerangka tertutup. Pada pemanasan $1235^{\circ} \mathrm{C}, \alpha$-gadolinium berubah menjadi bentuk $\beta$ yang memiliki struktur kubus berpusat badan (Tony et. al, 1998).

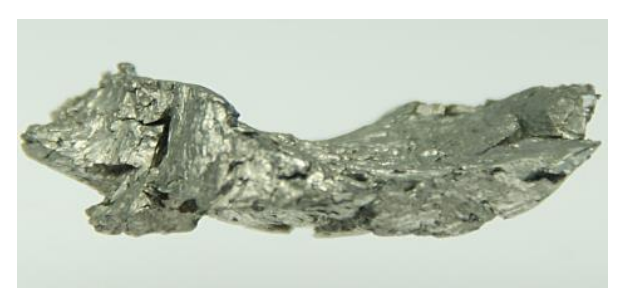

Gambar 3. gadolinium

Gadolinium relatif stabil di udara kering, tapi mudah kusam di udara lembab dan membentuk lapisan oksida yang menempel dengan lemah. Beraksi 
lambat dengan air dan mudah larut dalam asam encer. Gadolinium memiliki daya tangkap neutron termal tinggi dari semua unsur (Elsner, 2010).

Tabel 1 Sifat Fisik Gadolinium (Anker, 2010)

\begin{tabular}{lc}
\hline Sifat & Karakteristik \\
\hline Nomor atom & 64 \\
Berat molekul $(\mathrm{g} / \mathrm{mol})$. & 157,25 \\
Densitas $\left(\mathrm{g} / \mathrm{cm}^{3}\right)$ & 7,90 \\
Titik leleh $\left({ }^{\circ} \mathrm{C}\right)$ & 1312 \\
Titik didih $\left({ }^{\circ} \mathrm{C}\right)$ & 3250 \\
Konduktivitas termal $\left(\mathrm{Wm}^{-1{ }^{\circ}} \mathrm{K}^{-1}\right)$ & 11 \\
Sifat magnetik & Paramagnetik \\
Kristalografi & Heksagonal \\
\hline
\end{tabular}

\section{Asam di-2-(etilheksil)fosfat ( $\mathrm{D}_{2}$ EHPA) dan Tributilfosfat (TBP)}

$\mathrm{D}_{2}$ EHPA dan TBP merupakan ligan dari organofosfor. Kedua ligan ini telah banyak digunakan untuk memisahkan unsur-unsur UTJ secara ekstraksi pelarut. $\mathrm{D}_{2}$ EHPA di dalam pelarut non-polar berbentuk dimer, sedangkan di dalam pelarut polar, berbentuk monomer (Zamani dan Yaftian, 2004). Hasil ekstraksi menggunakan $\mathrm{D}_{2}$ EHPA semakin meningkat dengan meningkatnya nomor atom UTJ. Hal yang sama juga diperoleh bila $\mathrm{D}_{2}$ EHPA digunakan sebagai carrier untuk transport ion-ion UTJ dengan metode emulsi membran cair (Chitra dkk. ,1997).

TBP merupakan ligan yang bersifat netral dan relatif kurang selektif untuk pemisahan ion-ion logam dibandingkan dengan $\mathrm{D}_{2} \mathrm{EHPA}$, namun TBP dapat menimbulkan efek sinergis bila mana digabungkan dengan ligan $\mathrm{D}_{2}$ EHPA. Pada tahun 2004, Djunaidi meneliti bahwa semakin besar konsentrasi TBP pada perbandingan campuran $\mathrm{D}_{2}$ EHPA, maka efek sinergis yang ditimbulkan semakin besar. Apabila $\mathrm{D}_{2}$ EHPA dan TBP dicampurkan dengan perbandingan mol tertentu, dapat menimbulkan efek sinergis pada pemisahan ion-ion UTJ (Kraikaew, 2001).

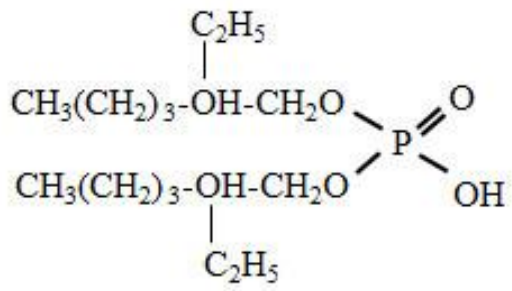

Gambar 4. Struktur Ligan D2EHPA<smiles>CCCCCOP(=O)(OCCCC)OCCCC</smiles>

Gambar 5. Struktur Ligan TBP

\section{METODE PENELITIAN}

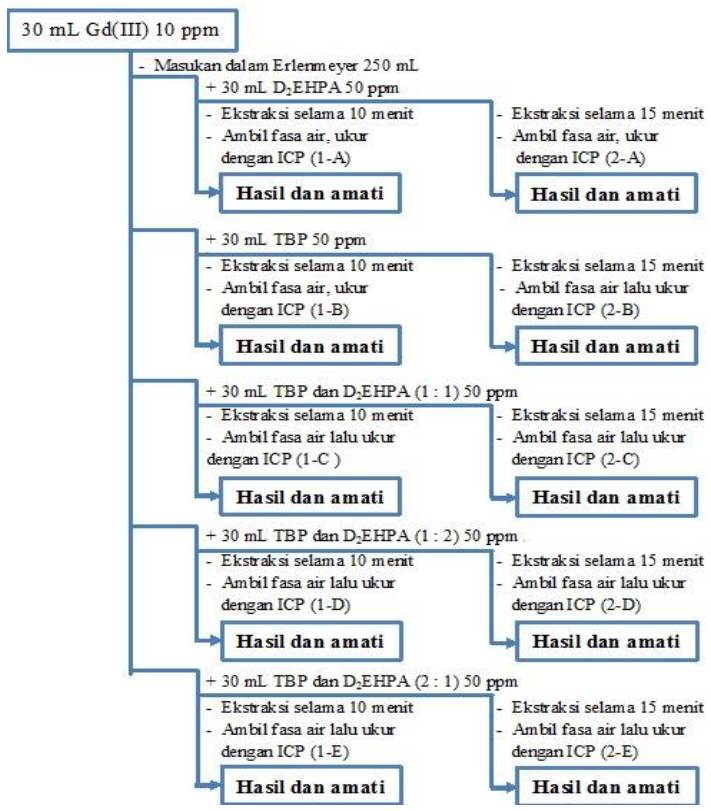

Gambar. 6. Diagram Alir Pemisahan $30 \mathrm{~mL}$ Gd(III) $10 \mathrm{ppm}$ 


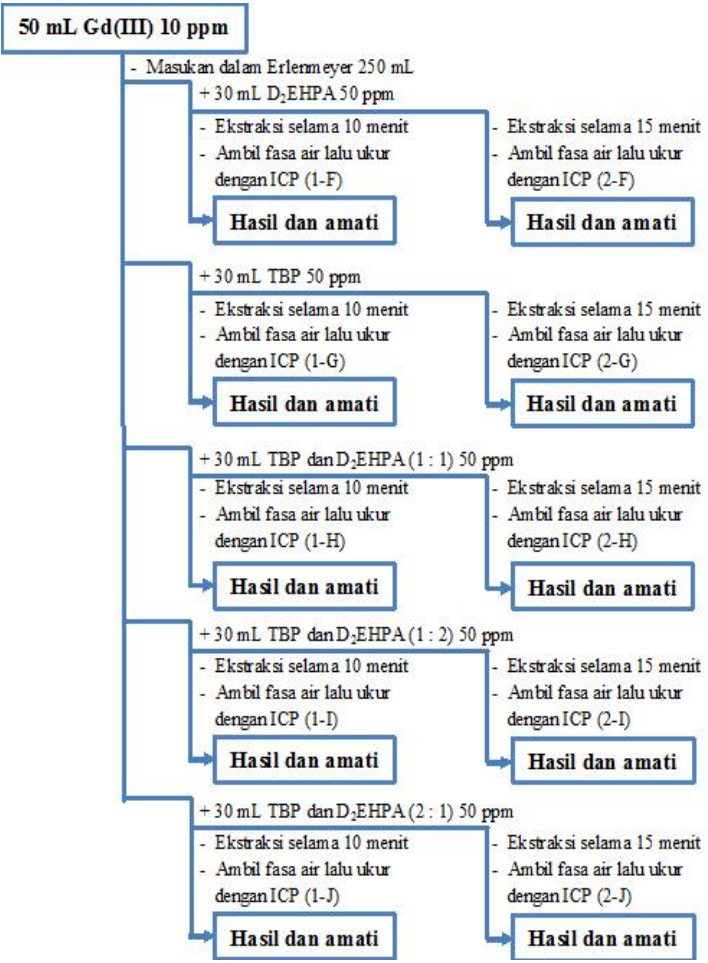

Gambar. 7. Diagram Alir Pemisahan $50 \mathrm{~mL}$ Gd(III) $10 \mathrm{ppm}$

\section{HASIL DAN PEMBAHASAN}

\section{Pengaruh ekstraksi meggunakan $D_{2}$ EHPA terhadap waktu dan volume 30 mL Gd(III) 10 ppm}

Tabel 2. Ekstraksi terhadap $D_{2}$ EHPA terhadap waktu terhadap [Gd(III)]

\begin{tabular}{ccc}
\hline Sampel & $\begin{array}{c}{[\mathbf{G d}(\mathbf{I I I})]} \\
\mathbf{1 0} \text { menit } \\
\mathbf{p p m}\end{array}$ & $\begin{array}{c}{[\mathbf{G d}(\mathbf{I I I})]} \\
\mathbf{1 5} \text { menit } \\
\mathbf{p p m}\end{array}$ \\
\hline 1-A & 0,1853 & - \\
$2-\mathrm{A}$ & 0,7446 & - \\
$1-\mathrm{B}$ & - & 0,2074 \\
2-B & - & 0,7596 \\
\hline
\end{tabular}

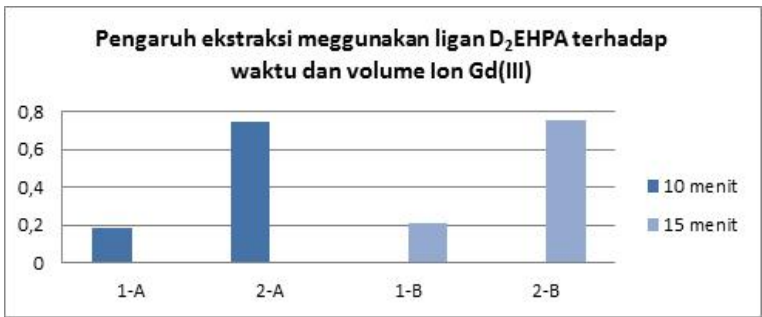

Gambar 8 Penggunaan D2EHPA terhadap Waktu dan Volume Gd(III)

Dari hasil uji menggunakan $\mathrm{D}_{2}$ EHPA terhadap waktu terlihat bahwa lama pengadukan memberikan hasil yang berbeda. Di tunjukan oleh tabel 2 pada sampel 1-A dan sampel 1-B hasil Gd(III) yang terukur memiliki selisih $0,0021 \mathrm{ppm}$ menunjukkan waktu pengadukan selama 10 menit adalah waktu yang optimal untuk mengikat Gd-D $\mathrm{D}_{2}$ EPA. Begitupula untuk sampel 2-A dan sampel 2-B menunjukan data yang serupa yaitu pada menit ke-10 menegaskan bahwa pada menit tersebut sisa $\mathrm{Gd}(\mathrm{III})$ hasil reaksi lebih sedikit dibanding 15 menit. Dari hasil tersebut, pengaruh konsentrasi Gd(III) tidak terlalu berpengaruh banyak karena dengan volume ligan $30 \mathrm{~mL}$ efisien terhadap volume Gd(III) $30 \mathrm{~mL}$, di tunjukan oleh data pada tabel 2 dimana terdapat selisih $\pm 1 \mathrm{ppm}$ antara volume logam 30 dan $50 \mathrm{~mL}$.

\section{Pengaruh ekstraksi meggunakan ligan TBP terhadap waktu dan $30 \mathrm{~mL}$ Gd(III).}

Tabel 3 Ekstraksi menggunakan TBP terhadap waktu dan volume $G d(I I I)$

\begin{tabular}{ccc}
\hline Sampel & $\begin{array}{c}{[\mathbf{G d}(\mathbf{I I I})]} \\
\mathbf{1 0} \text { menit } \\
\mathbf{p p m}\end{array}$ & $\begin{array}{c}{[\mathbf{G d}(\mathbf{I I I})]} \\
\mathbf{1 5} \text { menit } \\
\mathbf{p p m}\end{array}$ \\
\hline $1-\mathrm{C}$ & 0,2983 & - \\
$2-\mathrm{C}$ & 1,4629 & - \\
$1-\mathrm{D}$ & - & 0,3004 \\
$2-\mathrm{D}$ & - & 1,4827 \\
\hline
\end{tabular}


Pemisahan Gadolinium Sebagai Contrast Agent Pada Mri (Magnetic Resonance Imaging) Dengan Ligan Asam Di-(2-Etilheksil)Fosfat ( ${ }_{2}$ ehpa) Dan Tributilfosfat (Tbp) Secara Ekstraksi Cair-Cair Dengan Pelarut Organik-Kerosin

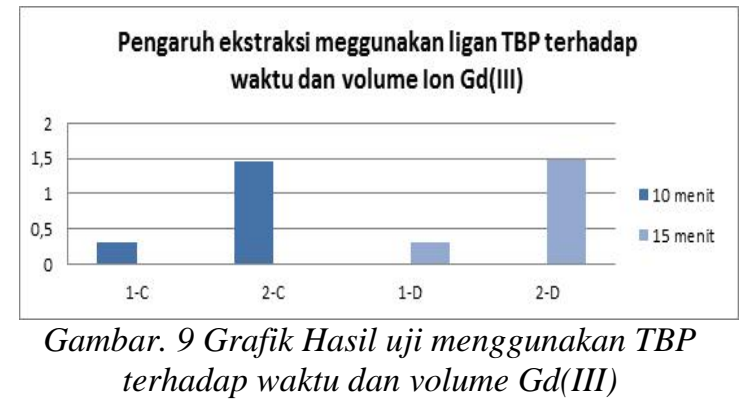

Hasil uji menggunakan TBP terhadap waktu dan $30 \mathrm{~mL} \mathrm{Gd(III)} \mathrm{terlihat} \mathrm{bahwa}$ hasil tersebut tidak jauh berbeda dengan hasil menggunakan $\mathrm{D}_{2}$ EHPA dan $30 \mathrm{~mL}$ Gd(III). Perbedaan dari penggunaan ligan tersebut adalah [Gd(III)] pada sampel uji dalam TBP lebih baik dibanding $\mathrm{D}_{2}$ EHPA untuk mengikat Gd(III).

\section{Pengaruh ekstraksi menggunakan TBP:D 2 EHPA (1:1) terhadap waktu dan volume Gd(III)}

Tabel 4 Ekstraksi menggunakan TBP: D2EHPA

(1:1) terhadap waktu dan volume larutan $G d(I I I)$

\begin{tabular}{ccc}
\hline Sampel & $\begin{array}{c}{[\mathbf{G d}(\text { III) }]} \\
\mathbf{1 0} \text { menit } \\
\mathbf{p p m}\end{array}$ & $\begin{array}{c}\text { [Gd(III) } \text { menit } \\
\mathbf{p p m}\end{array}$ \\
\hline $1-\mathrm{E}$ & 0,1219 & - \\
$2-\mathrm{E}$ & 0,7837 & - \\
$1-\mathrm{F}$ & - & 0,2884 \\
$2-\mathrm{F}$ & - & 0,8157 \\
\hline
\end{tabular}

Dari hasil uji ekstraksi menggunakan TBP:D 2 EHPA (1:1) terhadap waktu dan volume $\mathrm{Gd}(\mathrm{III})$ dapat terlihat bahwa kedua ligan tersebut memberikan efek sinergis yang membuat reaksi terhadap Gd(III) lebih baik.

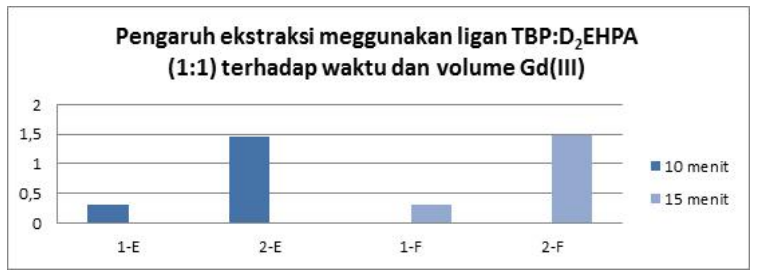

Gambar.10. Ekstraksi menggunakan TBP:

$D_{2}$ EHPA (1:1) terhadap waktu dan volume $G d(I I I)$

\section{Pengaruh ekstraksi menggunakan TBP:D2EHPA (2:1) terhadap waktu dan volume Gd(III)}

Pengaruh pada sampel 1-G hingga 2$\mathrm{H}$ lebih baik dibanding dengan $\mathrm{D}_{2} \mathrm{EHPA}$, namun masih lebih baik TBP: $\mathrm{D}_{2} \mathrm{EHPA}$ (1:1). Pengaturan komposisi yang efisien terhadap pengikatan Gd(III) di data ini kadar Gd(III) memiliki selisih yang lebih besar kisaran 0,3 hingga 0,4 ppm.

Tabel 5 Ekstraksi menggunakan TBP: D2EHPA (2:1) terhadap waktu dan volume larutan Gd(III)

\begin{tabular}{ccc} 
Sampel & $\begin{array}{c}{[\mathbf{G d}(\text { III })]} \\
\mathbf{1 0} \text { menit } \\
\text { ppm }\end{array}$ & $\begin{array}{c}\text { [Gd(III)] } \\
\text { Ppmit }\end{array}$ \\
\hline $1-\mathrm{G}$ & 0,1524 & - \\
$2-\mathrm{G}$ & 0,8216 & - \\
$1-\mathrm{H}$ & - & 0,1586 \\
$2-\mathrm{H}$ & - & 0,8674 \\
\hline
\end{tabular}

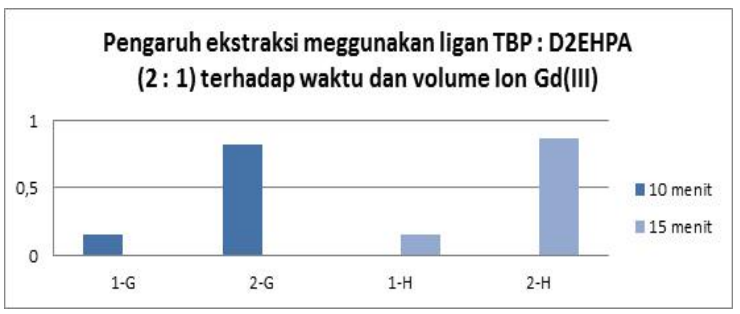

Gambar 11. Ekstraksi menggunakan TBP:

$D_{2} E H P A$ (2:1) terhadap waktu dan volume Gd(III) 


\section{Pengaruh ekstraksi menggunakan TBP : D2EHPA (1 : 2) terhadap waktu dan volume Gd(III)}

Tabel 6 Ekstraksi menggunakan TBP: $D_{2} E H P A$ (1:2) terhadap waktu dan Gd(III) $50 \mathrm{~mL}$

\begin{tabular}{ccc}
\hline Sampel & $\begin{array}{c}{[\mathbf{G d}(\text { III) }]} \\
\mathbf{1 0} \text { menit } \\
\text { ppm }\end{array}$ & $\begin{array}{c}\text { [Gd(III)] } \\
\mathbf{1 5} \text { menit } \\
\text { ppm }\end{array}$ \\
\hline $1-\mathrm{I}$ & 0,0958 & - \\
$2-\mathrm{I}$ & 0,6425 & - \\
$1-\mathrm{J}$ & - & 0,0974 \\
$2-\mathrm{J}$ & - & 0,6869 \\
\hline
\end{tabular}

Dari tabel 6 di dapat bahwa efek sinergis untuk perbandingan TBP : $\mathrm{D}_{2}$ EHPA (1:2) sangatlah baik, karena hasilnya yang paling kecil dibandingkan data-data dengan variasi bahkan ligan tunggalnya sekalipun. Di dapatkan konsentrasi terkecil pada pengadukan selama 10 menit dan konsentrasi $30 \mathrm{~mL}$ Gd(III) 10 ppm

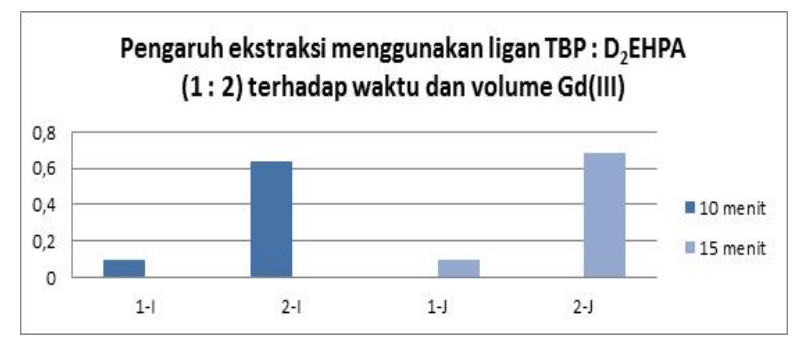

Gambar.12. Ekstraksi menggunakan TBP:

$D_{2}$ EHPA (1:2) terhadap waktu dan volume Gd(III)

Hal ini dimungkinkan dalam gambar 12 oleh efek sinergis yang dihasilkan oleh kedua ligan namun di imbangi dengan lebih banyaknya $\mathrm{D}_{2}$ EHPA pada kompisisi tersebut.

\section{KESIMPULAN}

Dari penelitian di atas dapat diambil kesimpulan :

1. Waktu ekstraksi yang optimal adalah 10 menit. Volume Gd(III) yang optimal penyerapannya pada $30 \mathrm{~mL}$.

2. Keterikatakan $\mathrm{Gd}(\mathrm{III})$ pada kondisi optimum tersebut, dengan $\mathrm{D}_{2}$ EHPA sebesar 93,92\% ; TBP 90,06\%, dan campuran $\mathrm{D}_{2}$ EHPA dan TBP $(1: 1)$ $95,94 \%$, dengan campuran ligan $\mathrm{D}_{2}$ EHPA dan TBP $(1: 2) 94,92 \%$ dan dengan campuran $\mathrm{D}_{2}$ EHPA dan TBP (2:1) $96,81 \%$.

\section{UCAPAN TERIMAKASIH}

Kami mengucapkan terimakasih kepada LPPM UNJANI yang telah memberikan dana bantuan penelitian TA 2016-2017 dalam rangka studi kami di Program Doktor FMIPA UNPAD.

\section{DAFTAR PUSTAKA}

[1]. Anker, T. 2010. Samarium(II)-mediated Reactions in Organic Synthesis Method Development and Mechanis-tic Investigation. $\mathrm{PhD}$ thesis, Depart-ment of Chemistry. University of Gothenburg.

[2]. Chitra, K.R., Gaikwad, A.G., Surender, G.D., dan Damodaran, A.D.,1997, Studies on Ion Transport of Some Rare Earth Elements Through Solvating Extractants Immobilised on Supported Liquid Membrane, Journal of Membrane Science, 125, 257-268.

[3]. Christie, Tony., Braithwaite, B. and Tulloch, A. 1998. Rare Earth and Related Elements. Mineral Commodity Report, 17.

[4]. Dwi Biyantoro, 2008, Teknologi Pemisa-han Itrium dari Pasir Senotim Untuk Industri, Orasi Pengukuhan Profesor Riset, Bidang Kimia dan Teknologi Proses Bahan BATAN p-ISSN: 1410-6957, e-ISSN: 2503-5029, Yogyakarta.

[5]. Elsner, H. 2010. Heavy Minerals of Economic Infortance. Assessment Manual Federal Institute of Geoscience and Natural Resource (BGR). Hannover, Canada 
[6]. Endang Suwargi, Bambang Pardiarto, Teuku Ishlah, 2010, Potensi Logam Tanah Jarang Di Indonesia, Buletin Sumber Daya Geologi ISSN 1907-5367 Volume 5 Nomor 3 - 2010, Bandung.

[7]. Fontana, and \& Loris, F. 2009. Separation of Middle Rare Earths by Solvent Extraction Using 2-Ethylheksyl phospohoric Acid Mono-2-Ethyl-heksyl Ester. Journal of Rare Earth. 27 : 830-833.

[8]. Gupta, C.K., Krishnamurthy, N., 2005. Extractive metallurgy of rare-earths. CRC Press. London.

[9]. Isyatun Rodliyah, 2015, Penelitian Logam Tanah Jarang di Indonesia, M\&E, Vol. 13, No. 1, Maret 2015, Pusat Penelitian dan Pengembangan Teknologi Mineral dan Batubara "tekMIRA", Bandung.

[10]. Kraikaew, J., Srinuttrakul, W., and Chayavadhanakur, C. 2005. Solvent Extraction Study of Rare Earth from Nitrate medium by the Mixtures of TBP and D2EHPA in Kerosene. Chemistry and Material Science Research Program. Bangkok

[11]. Mulyono Notosiswoyo , Susy Suswati, 2004, Pemanfaatan Magnetic Resonance Imaging (MRI) Sebagai Sarana Diagnosa Pasien, Media Litbang Kesehatan Volume XIV Nomor 3 Tahun 2004, jakarta.
[12]. Lars G. Hanson, 2009, Introduction to Magnetic Resonance Imaging Techniques, Danish Research Centre for Magnetic Resonance (DRCMR), Copenhagen University Hospital Hvidovre.

[13]. Thomita, A., T. Kanki., N. Sano., T. Asano and S.Imai, 2003, On the Mexhanism of the Interfacial Reaction in Extraction of Rare Earth Metals by D2EHPA. J.Chem.Eng. Mineral Pro-cess. 11 : 539-555.

[14]. Tormod Fjerdrumsmoen, 2004, Synthesis and evaluation of new gadolinium based MRI contrast agents, Department of Medical Chemistry Faculty of Mathematics and Natural Sciences University of Oslo, Norwegia.

[15]. Tri Handini, Bambang EHB, Sri Sukmajaya, Ekstraksi Y, Dy, Gd Dari Kon-sentrat Itrium Dengan Solven TBP, D2EHPA, Ganendra Journal of Nuc-lear Science and Technology Vol. 20 No. 1, Januari 2017: 49 - 55 p-ISSN: 1410-6957, e-ISSN: 25035029

[16]. Zamani, A.A., dan Yaftian, M.R., 2004 Solvent Extraction of Thorium, Lanthanum and Europium Ions by $\operatorname{Bis}(2-$ ethylhexyl)phosphoric Acid Using 2nitrobenzo-18-crown-6 as Ion Size Selective Masking Agent. Separation and Purification Technology, 40, 115-121. 